\title{
A influência da reflexividade verbal no processamento anáfora se
} The verbal reflexivity's influence in anaphora se processing

\author{
Judithe Genuíno Henrique ${ }^{1}$, Rosana Costa de Oliveira², Flávia Gonçalves Calaça de Souza ${ }^{3}$
}

Graduada em Letras, com habilitação em língua portuguesa, pela Universidade Federal da Paraiba. Mestre em Linguistica (UFPB). Atualmente doutoranda em Linguística (UFPB)

E-mail: juathegh@gmail.com Laboratório de Processamento lingquisadora do

E-mail: rosana.ưtpb@@gmail.com portuguesa, pela Universidade Federal da Paraíba. Mestre em Linguística (UFPB). Atualmente doutoranda em Linguistica (UFPB).
RESUMO: A pesquisa elaborada neste estudo investiga a reflexividade verbal e seu papel no processamento da anáfora se. No intuito de verificar quais verbos são considerados mais aceitáveis na leitura de sentenças contendo a anáfora se, realizamos um teste offline de julgamento de aceitabilidade com falantes nativos do português brasileiro. Utilizamo-nos da noção de reflexividade proposta por Reinhart e Reuland (1993), os quais predizem que a reflexividade é uma propriedade dos predicados, bem como dos trabalhos de Christiano (1991) e Mello (2008), pois estes estabeleceram uma classificação mais categórica para os verbos com características mais reflexivas, dividindo-os em três níveis: primário - penteou, secundário sentou, e terciário - acusou, de acordo com o grau de reflexividade. De modo geral, os resultados encontrados evidenciaram que a propriedade da reflexividade pode estar presente tanto na anáfora como no predicado, assim como afirmam Reinhart e Reuland (1993).

Palavras-chave: Reflexividade; Anáfora; Aceitabilidade.

ABSTRACT: The research elaborated in this study investigates verbal reflexivity and its role in the processing of anaphora se. In order to verify which verbs are considered more acceptable in the reading of sentences containing the anaphora self, we performed an offline test of acceptability judgment with native speakers of Brazilian Portuguese. Reinhart \& Reuland (1993), who predict that reflexivity is a property of the predicates, as well as the works of Christiano (1993) and Mello (2008), have established a more categorical classification for reflexivity. The verbs with more reflexive characteristics, dividing them into three levels: primary - combed, secondary - sat, and tertiary - accused, according to their degree of reflexivity. In general, the results showed that the property of reflexivity can be present in both the anaphora and the predicate, as Reinhart \& Reuland (1993) states.

Keywords: Reflexivity; Anaphora; Acceptability. 


\section{Introdução}

objetivo deste trabalho é investigar a reflexividade verbal e o seu papel no processamento anafórico. Traçaremos um percurso teórico desde a Teoria da Ligação (Binding Theory, CHOMSKY, 1981, 1986) de cunho gerativista, que visa explicar sintaticamente a referenciação de anáforas e pronomes, até os estudos da Teoria da Reflexividade (REINHART e REULAND, 1993) ${ }^{1}$, que trouxeram uma nova interpretação para a Teoria da Ligação, afirmando que a reflexividade é uma propriedade dos predicados e não dos nominais, como prediz Chomsky $(1981,1986)$. Adiante elencaremos alguns trabalhos que trazem a abordagem sintática de Chomsky (1981) e outros que envolvem a influência verbal no processamento e aquisição anafórica e pronominal.

De modo geral, investigaremos se somente a informação referente à atuação dos princípios de ligação é a única que estabelece a correferência de expressões anafóricas, ou se esse processo é afetado por outros fatores, como a semântica verbal.

Muitos estudos, tanto na língua portuguesa quanto em outras línguas, buscam aproximar as teorias linguísticas dos estudos psicolinguísticos. Trabalhos que envolvem processamento anafórico na língua inglesa como os de Nicol e Swinney (1989) e os de Oliveira, Leitão e Henrique (2012), no português brasileiro, investigaram a atuação dos princípios estruturais da Teoria da Ligação e encontraram resultados que apontam somente a influência de questões sintáticas no processamento das anáforas. Outros trabalhos indicam a influência de questões tanto estruturais quanto semânticas no processamento e aquisição da linguagem, como os estudos de Grolla (2012) e Lacerda (2014). Nos estudos de Grolla (2012), foram encontradas influências da semântica verbal na aquisição da expressão anafórica "ele mesmo", assim

\footnotetext{
${ }^{1}$ De agora em diante R\&R.
}

como no trabalho de Lacerda (2014), o qual investigou os diferentes tipos de retomadas [se, nulo e ele (a)]. Por meio de um experimento online, Lacerda (2014) encontrou evidências que comprovaram a influência do tipo de verbo no processamento dessas estruturas com anáforas reflexivas.

Foi a partir desses trabalhos que surgiu a necessidade investigativa de pesquisar o processamento anafórico, com ênfase na anáfora se, aliada a verbos com características reflexivas, como "penteou”, "banhou" e "vestiu”, por exemplo, e de observar se a semântica verbal influencia no processamento anafórico.

Para embasar nossa pesquisa, realizamos um teste de julgamento de aceitabilidade. O teste foi offline, desenvolvido no Google Forms. O experimento foi apresentado aos participantes na tela do computador. Cada participante respondia ao seu teste e, logo em seguida, clicava na opção "enviar", que garantia o envio para o $e$-mail solicitado. 0 experimento buscou estabelecer qual verbo da língua portuguesa seria mais aceitável na presença da anáfora se e sintagmas nominais, tendo como critério para classificação desses verbos os trabalhos de Christiano (1991) e Mello (2008).

Apostamos na premissa de que a referenciação não se constitui apenas de fatores sintáticos, como prediz Chomsky (1981), mas que fatores semânticos podem atuar na interpretação de sentenças reflexivas, assim como encontrado nos trabalhos experimentais de Grolla (2012) e Lacerda (2014). Diante do postulado, temos como hipótese inicial a de que os verbos reflexivos, de acordo com a nomenclatura estabelecida por Christiano (1991) e Mello (2008), influenciam na leitura de frases contendo anáforas.

\section{Fundamentação Teórica}

\subsection{Teoria da Ligação (BindingTheory)}

A Teoria da Ligação (Binding Theory, CHOMSKY, 1981) tem como objetivo estudar as relações correferenciais dentro do escopo da sentença. Essa teoria 
busca fornecer subsídios que deem conta de organizar e explicar como nossa cognição estabelece a referenciação de expressões nominais e pronominais. Para isso, Chomsky (1981) postulou três princípios, sendo eles:

- Princípio A - Uma anáfora deve ser presa no seu domínio de ligação.

- Princípio B - Um pronome deve ser livre no seu domínio de ligação.

- Princípio C - Uma expressão R-referencial deve ser livre. ${ }^{2}$

Quando nos referimos a domínio de ligação ou domínio de regência, estamos estabelecendo o limite que contém a anáfora e seu antecedente, ou seja, o menor $\mathrm{XP}^{3}$ que contém a anáfora. Com relação à definição de ligação, temos o seguinte esquema formulado por Chomsky (1981):

Ligação:

A se liga a B se e somente se

(i) A c-comanda B;

(ii) A e B são coindexados.

O Princípio A, referente às anáforas reflexivas, como o se, por exemplo, e anáforas recíprocas, como um ao outro, afirma que uma anáfora deve estar ligada por um antecedente que esteja a c-comandando e em seu domínio local. Entendemos por c-comando a noção sintática de vínculo entre dois constituintes. De acordo com Kenedy (2013), $\alpha$ c-comanda $\beta$ se e somente se: $\alpha$ é um constituinte diferente de $\beta, \alpha$ não domina $\beta, \beta$ não domina $\alpha$ e todo nódulo sintático que domina $\alpha$ também domina $\beta$.

O Princípio B defende que todo pronome deve ser livre em seu domínio de vinculação, ou seja, o pronome e seu antecedente não podem estar na mesma sentença. Analisemos os exemplos a seguir:

\footnotetext{
2 Binding Principles (CHOMSKY, 1986):

A. An anaphor must be A-bound in its binding domain.

B. A pronominal must be A-free in its binding domain

C. An R-expression must be A-free.

3 Projeção Máxima.
}

a. [ Carol $_{i}$ pensa que [Maria vestiu ela ${ }_{i}$ com a blusa.]]

b. *[Carol pensa que [Maria ${ }_{i}$ vestiu ela $_{i}$ com a blusa.]]

A sentença (a) é totalmente gramatical, pois o seu antecedente está fora do domínio de ligação do pronome. Já a sentença (b) é agramatical, em termos da Teoria da Ligação, pelo fato de o pronome "ela" ser correferente a "Maria", quando na verdade dever-se-ia usar um anafórico no lugar do pronome, como o se, por exemplo.

O Princípio C rege as expressões- $\mathrm{R}$ e propõe que elas devem ser livres em todas as ocorrências, isto é, elas não irão depender de um antecedente, pelo fato de possuírem características referenciais, como podemos observar no exemplo abaixo:

O Pedro observou o Carlos no evento.

Com o intuito de trazer uma nova visão a respeito da Teoria da Ligação, R\&R (1993) apresentam uma abordagem que explica a distribuição complementar entre anáforas e pronomes. Essa teoria prediz que a reflexividade é uma propriedade dos predicados e não dos nominais, como afirma Chomsky $(1981,1986)$, o que traz, assim, uma outra ótica para os Princípios A e B (Binding Theory, CHOMSKY, 1981). Veremos adiante como essa proposta se define.

\subsection{Reflexividade (Reflexivity)}

Diante do que foi postulado pela Teoria da Ligação (CHOMSKY, 1981; 1986) a respeito das condições A e B, R\&R (1993) propuseram duas teorias: a Teoria da Reflexividade dos predicados e a Teoria de Cadeia, ambas como forma de realizar uma nova interpretação para a Teoria da Ligação.

Os autores iniciam seu trabalho fazendo uma divisão dos tipos de expressões anafóricas lexicais, classificando-as em pronomes, que se realizam 
em posição de $\mathrm{DP}^{4}$, e anáforas, sendo estas subdivididas em: Anáforas $\mathrm{SE}$, que são consideradas como anáforas simples e que podem estabelecer ligação à distância, e Anáforas SELF, que, ao se ligarem a um elemento pronominal, são consideradas compostas e locais, não podendo se ligarem à distância.

Para estabelecer uma distinção entre as propriedades referenciais de anáforas, pronomes e expressões- $R, R \& R$ (1993) realizaram uma divisão com relação à adoção de traços para cada elemento, conforme podemos observar na tabela abaixo:

Tabela 1 - Quadro apresentado por Reinhart e Reuland (1993) sobre as propriedades referenciais de anáforas e pronomes.

\begin{tabular}{lccc}
\hline & Anáforas SELF & Anáforas SE & Pronome \\
Reflexividade & + & - & - \\
Independência referencial & - & - & + \\
\hline
\end{tabular}

R\&R (1993) afirmam que a marcação dos itens lexicais está ligada ao traço $[ \pm R]$. Quando temos um item como [+R], significa que este possui traços de pessoa, número, gênero e caso; se não possuir esses caracteres, se torna $[-R]$, conforme apresentado na tabela acima. Percebemos que, para R\&R, tanto as anáforas SE como os pronomes são [-R], sendo, portanto, menos reflexivizadores.

Assim, R\&R (1993) predizem que a reflexividade é uma propriedade dos predicados e, para isso, propõem duas condições:

- Condição A: Um predicado marcado - sintático - reflexivo é reflexivo.

- Condição B: Um predicado reflexivo - semântico - é marcado reflexivo. ${ }^{5}$

\footnotetext{
Binding Conditions (R\&R, 1993):

Condition A: A reflexive-marked - syntactic - predicate is reflexive.

- Condition B: A reflexive - semantic - predicate is reflexive-marked.
}

O predicado pode ser reflexivo: se nele dois de seus argumentos forem coindexados, ou se possuírem um verbo lexicalmente reflexivo em relação ao argumento indexado, ou, ainda, se um dos argumentos indexados é uma anáfora SELF.

A Condição A prediz que, quando existe no predicado a coindexação entre a anáfora e seu argumento, bem como esse argumento já está marcado lexicalmente, o predicado é reflexivo.

A Condição B afirma que os coargumentos de um predicado que não possuem a propriedade de serem intrinsecamente reflexivos só podem ser coindexados quando um dos argumentos for uma anáfora SELF, assim, o predicado é marcado reflexivo pela presença desse tipo de anáfora.

Observemos a sentença apresentada por R\&R abaixo:

$\operatorname{Max}_{1}$ criticized himself $_{1 .}{ }^{6}$

Nessa sentença o predicado é reflexivo e reflexivo marcado. Reflexivo porque os dois argumentos estão coindexados e reflexivo marcado pelo fato da presença do traço SELF na anáfora himself.

Como podemos perceber, o comportamento de expressões anafóricas para R\&R (1993) não está relacionado às restrições dos Princípios de Ligação (CHOMSKY, 1981), mas essa relação acontece pela reflexividade dos predicados.

Diante dos modelos teóricos apresentados, a Teoria da Ligação (Binding Theory, CHOMSKY, 1981, 1986) e a Teoria da Reflexividade (REINHART e REULAND, 1993), observamos que há diferentes perspectivas que abordam a resolução da referência de anáforas e pronomes e que se fazem imprescindíveis nos estudos que regem fatores tanto sintáticos como semânticos.

6 Max criticou a ele mesmo. 
Partindo do que foi postulado por R\&R (1993) a respeito da noção de reflexividade e de sua propriedade do item intrinsecamente marcado no léxico, no caso, o verbo deixar a sentença reflexiva, decidimos verificar a aceitabilidade de sentenças contendo verbos reflexivos e anáforas.

Assim, por não haver uma delimitação precisa, tanto nas gramáticas tradicionais como nos trabalhos em processamento, do que podemos considerar por verbos de natureza reflexiva, na próxima seção traremos trabalhos de cunho funcionalista que realizaram uma divisão categórica para os verbos considerados reflexivos, sendo esta a divisão utilizada na pesquisa em questão.

\subsection{Christiano (1991)}

Christiano (1991) realizou uma pesquisa descritiva e propôs uma reformulação para as gramáticas tradicionais, em busca de trazer um estudo mais detalhado para estruturas da língua portuguesa tradicionalmente chamadas de 'pronominais' ou 'reflexivas'. Para realizar tal estudo, Christiano (1991) toma como base as relações sintáticas e semânticas entre o verbo e a correlação que este mantém com os outros elementos que compõem a oração, fazendo uma reanálise dos verbos 'reflexivos', assim como dos pronomes correferenciais 'reflexivos' e 'recíprocos'.

Christiano (1991) fundamenta sua pesquisa em três importantes propostas, sendo elas: "A Teoria dos Casos Profundos", mais conhecida como "A Gramática dos Casos", de Charles Fillmore (1968), a qual busca explicar como ocorrem as relações sintático-semânticas entre o verbo - predicador - e os nomes - casos - que acompanham o verbo; o modelo de Chafe (1970), que "[...] enfatiza a centralidade da semântica e a proeminência do verbo na estrutura semântica." (CHRISTIANO, 1991, p. 61); e, por fim, o modelo matriz de Cook (1972), pelo fato de este fazer uma união equilibrada dos estudos de Fillmore e Chafe, propondo, por meio de uma perspectiva mais semântica, um redimensionamento da Teoria dos Casos.

O início do estudo relata uma revisão histórica a respeito das vozes do verbo, para adiante apresentar a relação entre as estruturas reflexivas e a voz medial. Diante desse estudo, Christiano (1991) reanalisa a reflexividade verbal e propõe um novo modelo para as construções pronominais ou reflexivas, tomando como base a Gramática dos Casos.

Christiano (1991) realiza uma divisão dos verbos em grupos e subgrupos conforme suas características sintáticas e semânticas, com o objetivo de estabelecer "generalizações que expressem uma motivação para a ocorrência ou não do pronome reflexivo" (CHRISTIANO, 1991, p. 115.). Diante dessa classificação, também estabelece níveis para a 'voz reflexiva', apresentados posteriormente.

O erro apontado por Christiano (1991), cometido pelos gramáticos, está na classificação e definição superficiais dadas aos verbos reflexivos, pois considerar esses verbos como acidentalmente pronominais, apenas, como é o caso da maioria das gramáticas tradicionais ou, somente, como reflexivos não é suficiente para compreendermos seus aspectos sintáticos e semânticos. Outro aspecto apontado por ela como falha nos estudos dos verbos reflexivos é a forma de agrupá-los na mesma categoria sem que eles pertençam a ela.

Para tanto, Christiano (1991) faz uma análise mais profunda para os verbos reflexivos e propõe uma divisão desses verbos em nove grupos e alguns subgrupos para posteriormente apresentar os níveis de reflexividade que utilizaram os verbos desses grupos.

A partir dessa classificação, Mello (2008) construiu uma tabela com a distribuição dos verbos feita por Christiano (1991), fazendo uma inversão, apenas, do grupo 3 e 4 . Vejamos: 
Tabela 2 - Grupos verbais e níveis de reflexividade.

\begin{tabular}{|l|c|c|c|c|}
\hline \multicolumn{1}{|c|}{ Grupos Verbais } & \multicolumn{3}{|c|}{ Níveis de Reflexividade } \\
\cline { 2 - 5 } & Plena & Primária & Secundária & Terciária \\
\hline $\begin{array}{l}\text { G(D: tipo padrão: irritar-se } \\
\text { tipo padrão: encontrar-se }\end{array}$ & & & & $\mathrm{X} / \mathrm{X}$ \\
\hline $\begin{array}{l}\text { G(2): tipo padrão: queixar-se } \\
\text { tipo padrão: acusar-se }\end{array}$ & & $\mathrm{X}$ & & $\mathrm{X}$ \\
\hline G(3): tipo padrão: ajoelhar-se & & & $\mathrm{X}$ & \\
\hline G(4): tipo padrão: pentear-se & & $\mathrm{X}$ & & \\
\hline G(5): tipo padrão: lançar-se & & $\mathrm{X}$ & & \\
\hline G(6): tipo padrão: achar-se & & $\mathrm{X}$ & & \\
\hline G(7): tipo padrão: arrogar-se & & $\mathrm{X}$ & & \\
\hline G(8): tipo padrão: atrever-se & & & & $\mathrm{X}$ \\
\hline G(9): tipo padrão: encontrar-se & & $\mathrm{X}$ & & \\
\hline
\end{tabular}

Além da divisão dos verbos em grupos e subgrupos, Christiano (1991) propõe níveis de reflexividade, que são: pleno, primário e secundário, como apresentado na tabela acima, frisando que o nível terciário, nomenclatura dada por Mello (2008), é denominado de pseudo-reflexivo por Christiano (1991). Tanto a divisão dos grupos como a dos níveis de reflexividade foram feitas baseando-se nos trabalhos de Fillmore (1968) e Chafe (1970).

A noção de reflexividade usada por Christiano (1991) para esta pesquisa é caracterizada como um fenômeno que ocorre quando o sujeito e o objeto são correferentes em uma oração. Os níveis de reflexividade foram estabelecidos para ampliar o conceito dado para a 'voz-reflexiva', também conhecida como 'voz média', conforme podemos observar no trecho destacado de Christiano (1991):

[...] o pronome se com valor reflexivo está diretamente relacionado à significação do verbo. Assim, os verbos por nós arrolados (cf. item 2 deste capítulo) apresentam, na realidade, algumas particularidades com relação à diátese reflexiva. Daí a necessidade de se estabelecerem gradações para este tipo de voz. (CHRISTIANO, 1991, p. 167).

Como pode ser observado, os níveis de reflexividade se estabelecem pela voz reflexiva, definida como "[...] a forma verbal que indica que o sujeito é, ao mesmo tempo, agente e paciente da ação verbal [...]" (CHRISTIANO, 1991, p. 167). Assim, Christiano (1991) dividiu os verbos em três níveis de reflexividade, afirmando que os verbos possuem comportamentos diferentes com relação a esses níveis, tais como: a reflexividade plena, primária e secundária.

Comecemos pela reflexividade plena. Nesta o paciente sempre será igual e correferente ao agente, como podemos observar na sentença abaixo:

(1) 0 presidiário suicidou-se. ${ }^{7}$

A reflexividade primária inclui verbos que projetam a ação reflexiva, isto é, haverá nas sentenças um sujeito e complemento correferentes e reflexivos (2). Nesse nível de reflexividade também se encaixam os verbos que indicam reciprocidade (3), também possuindo um sujeito que pode ser agente e paciente. Vejamos:

(2) O ministro questionou-se diante de todos.

(3) Os dois adversários olhavam-se com rancor.

A reflexividade secundária se caracteriza por permitir a omissão total do reflexivo se na estrutura superficial, como pode ser observado abaixo:

(4) Juliana sentou-se para recuperar o fôlego.

7 As sentenças utilizadas nos exemplos (1), (2), (3), (4) e (5) foram retiradas da tese de doutorado de Christiano (1991) 
Christiano (1991) deixa de fora dos níveis de reflexividade as estruturas que possuem o se como pseudo-reflexivo. Elas são excluídas pelo fato de ocorrerem como pronominais. Vejamos:

(5) Solange aborreceu-se.

Neste caso não ocorre reflexividade, pois o verbo 'aborrecer' não é usado agentivamente, havendo uma marca de recessividade de um causador externo ao processo verbal. Nos estudos de Faltz (1985), ele amplia a possibilidade de o sujeito ser não só agente, mas também experienciador.

Foi a partir do objetivo de apresentar uma nova proposta de análise sintático-semântica das estruturas do português brasileiro que são vistas na forma 'pronominal' ou 'reflexiva' que se realizou uma redefinição e reclassificação dos verbos reflexivos e do pronome 'se', frisando que esta divisão não foi feita apenas "pela especificação dos esquemas casuais nos quais eles estão inseridos, mas também pelas suas propriedades derivacionais (possibilidade de sofrer derivação decausativa, resultativa, etc.)" (CHRISTIANO, 1991, p. 196).

Assim, conclui-se que, nas estruturas do português brasileiro, podem-se encontrar nove grupos de verbos pronominais ou reflexivos e três níveis de voz reflexiva: a reflexividade plena, a reflexividade primária e a reflexividade secundária.

\subsection{Mello (2008)}

Mello (2008), por sua vez, busca reunir, relacionar e organizar em grupos os diversos usos do se com função reflexiva, nos vários tipos de textos, com o objetivo de estabelecer suas funcionalidades - partícula de realce e pseudoreflexivo - no discurso. Para esse fim, toma como hipótese a de que o se passará por um processo de gramaticalização e isso fará com que ele passe de uma "categoria-fundante de clítico reflexivo a uma nova categoria de afixo verbal" (MELLO, 2008, p. 36). O corpus utilizado para observar esse fenômeno foram manuscritos oitocentistas da Paraíba escritos no século XVIII e XIX.

Assim, a autora procurou, por meio dos conceitos de marcação linguística, fazer observações sobre os níveis de reflexividade, visando "[...] aprender o uso produtivo do pronome se reflexivo no português do século XIX falado na Paraíba." (MELLO, 2008, p. 39).

Mello (2008) afirma que o se que possui valor reflexivo está intimamente relacionado à significação verbal. Diante disso, ela faz uma reanálise dos níveis de reflexividade estabelecidos por Christiano (1991), a qual altera apenas um nível. Mello (2008) acrescenta o nível terciário, conforme já observamos na Tab. 2 apresentada anteriormente.

Observemos abaixo a Tabela $3 \mathrm{com}$ as ocorrências do pronome se com alguma carga de reflexividade nas 152 cartas analisadas por Mello (2008):

Tabela 3 - Ocorrências do pronome reflexivo pelos níveis de reflexividade

\begin{tabular}{|c|c|c|}
\hline Níveis & Ocorrências/total & $\%$ \\
\hline Primário & 92/ 152 & 65 \\
\hline Secundário & 19/ 152 & 8 \\
\hline Terciário & $41 / 152$ & 27 \\
\hline Total & $152 / 152$ & 100 \\
\hline
\end{tabular}

Como podemos observar, o maior número de ocorrências, frequência, da forma se está no nível primário. Diante desse resultado, definiu-se uma escala de marcação, conforme pode ser visto na Figura 1 a seguir: 
Figura 1 - Escala de marcação: a frequência dos níveis

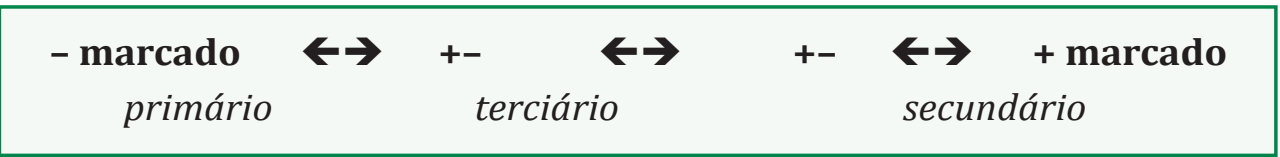

Fonte: As autoras

Existem critérios que definem a escala de marcação dos níveis. 0 primeiro critério aplicado neste estudo é o da complexidade estrutural, definido como "[...] a estrutura marcada tende a ser mais complexa ou maior do que sua correspondente não marcada" (CUNHA, BISPO e SILVA, 2013, p. 24). Quando temos as expressões junto com verbos do nível secundário, elas serão [- marcadas] devido à possibilidade da presença ou ausência do se. Já com relação às expressões com verbos de nível primário, elas são [+ marcadas], e isso acontece pelo fato da presença obrigatória do clítico se. Diante do nível terciário, temos expressões [+ marcadas] devido a não correferência entre sujeito e objeto.

O segundo critério que define a escala de marcação dos níveis com relação à função do se é a complexidade cognitiva: “[...] a categoria marcada tende a ser cognitivamente mais complexa - em termos de esforço mental, demanda de atenção ou tempo de processamento - do que a não marcada" (CUNHA, BISPO e SILVA, 2013, p. 24). Aplicando esse critério, os níveis de reflexividade terão outra configuração da figura 1 apresentada acima. 0 nível primário será considerado menos marcado que o secundário e terciário. Isso ocorre pelo fato de o se ser facultativo no nível secundário, necessitando de um maior esforço cognitivo, bem como no nível terciário, que não considera o se como um reflexivo, havendo um maior trabalho mental pelo falante.

Diante do estudo diacrônico da língua realizado neste trabalho com os falantes do português da cidade de João Pessoa, observou-se que o se aliado a verbos "[...] que não cumprem a condição primeira de reflexividade: a ação que parte de um sujeito e recai nele próprio" (MELLO, 2008, p. 44) passou por um processo de rotinização e inovação que o fez se modificar ao longo dos anos, isto é, sofreu uma gramaticalização, o que o deixou mais abstrato em seu uso.

Será com base na categorização da reflexividade dos verbos secundários, que iremos descrever um experimento de julgamento de aceitabilidade desses verbos em frases anafóricas, visto que a categorização verbal nos estudos em processamento linguístico e nas gramáticas tradicionais não dão conta de abarcar todas as nuances que o assunto engloba.

Assim, apresentaremos, na próxima seção, o surgimento e o desdobramento dos trabalhos em processamento anafórico, mediante a necessidade de compreender como ocorre o processamento da linguagem humana, bem como de expor as pesquisas que encontraram, incipientemente, resultados que vão além dos princípios da Teoria da Ligação (CHOMSKY, 1981; 1986), isto é, a influência de fatores semântico-discursivos.

\section{Estudos em processamento da linguagem}

Estudos em aquisição e processamento, como os de Grolla (2012) e Lacerda (2014), encontraram resultados significativos que comprovam a influência da semântica verbal em seus resultados. Foi a partir desses trabalhos que surgiu o interesse investigativo de desvendar até que ponto os verbos interferem no processamento dos falantes.

Grolla (2012) realizou um experimento de seleção de figuras, investigando a aquisição da forma anafórica 'ele mesmo' em português brasileiro. 0 estudo analisou como as crianças se comportariam quando fossem apresentadas à forma anafórica 'ele mesmo' e um verbo, classificado intuitivamente de preferencialmente reflexivo - 'pentear' - ou preferencialmente recíproco - 
'abraçar'. O objetivo central desse trabalho foi analisar se as crianças (até os seis anos) atribuiriam à expressão 'ele mesmo' uma interpretação reflexiva, ou se questões pragmáticas seriam levadas em consideração, como também a semântica do verbo, ou ainda se as respostas seriam aleatórias. Também se testou a forma $s e$, a fim de verificar se o comportamento seria igual à expressão anafórica 'ele mesmo'.

O experimento foi feito com 63 crianças, divididas em três grupos: grupo 1: 20 crianças entre 3;11 e 4;11 anos de idade; grupo 2: 20 crianças entre 5;0 e 5;11 anos; e grupo 3: 23 crianças entre 6;0 e 6;11 anos. As sentenças foram construídas a partir de quatro verbos, sendo dois preferencialmente reflexivos - 'pentear' e 'vestir' - e dois preferencialmente recíprocos - 'beijar' e 'abraçar', como podemos averiguar abaixo:

(6) Elas mesmas: apenas leitura reflexiva

a. Verbo recíproco + Elas mesmas

As meninas estão abraçando / beijando elas mesmas.

b. Verbo reflexivo + Elas mesmas

As meninas estão penteando /vestindo elas mesmas.

Se: reflexivo ou recíproco

Verbo recíproco + se

As meninas estão se abraçando / beijando.

Verbo reflexivo + se

As meninas estão se penteando / vestindo.

Observemos a Tabela 4, adiante, feita por Grolla (2012) com a frequência das respostas de cada grupo.

Os resultados apontam que as crianças do grupo 1 (crianças aos 4 anos) escolheram figuras de acordo com o verbo quando a forma era o reflexivo 'se'. Com a expressão anafórica 'ele mesmo', escolheram figuras reflexivas de acordo com a anáfora em apenas $41,25 \%$ das vezes. Nesse grupo obtiveram respostas divergentes para o 'se' e 'ele mesmo'. As crianças tiveram maior facilidade na escolha do 'se'.

Tabela 4 -Taxas de comportamento para 'se' e 'ele mesmo'

\begin{tabular}{ccc}
\hline Faixas etárias & 'Se' & 'Ele Mesmo' \\
G1 (4 anos) & $66,25 \%$ & $41,25 \%$ \\
G2 (5 anos) & $80 \%$ & $65 \%$ \\
G3 (6 anos) & $79,35 \%$ & $50 \%$ \\
Adultos & $82,85 \%$ & $100 \%$ \\
\hline
\end{tabular}

Os resultados apontam que as crianças do grupo 1 (crianças aos 4 anos) escolheram figuras de acordo com o verbo quando a forma era o reflexivo 'se'. Com a expressão anafórica 'ele mesmo', escolheram figuras reflexivas de acordo com a anáfora em apenas $41,25 \%$ das vezes. Nesse grupo obtiveram respostas divergentes para o 'se' e 'ele mesmo'. As crianças tiveram maior facilidade na escolha do 'se'.

No grupo 2 (crianças aos 5 anos), escolheram, 80\% das vezes, figuras de acordo com o verbo diante da forma 'se'. Já com a expressão 'ele mesmo', as crianças escolheram figuras reflexivas somente em $65 \%$ das vezes.

No grupo 3 (crianças aos 6 anos), as crianças escolheram, em 79,35\% das vezes, figuras de acordo com o verbo unido à forma 'se'. Em relação à expressão 'ele mesmo', escolheram, em apenas $50 \%$ das vezes, as figuras reflexivas.

Os resultados apontam que as crianças, mesmo aos 6 anos de idade, adquirem a expressão anafórica 'ele mesmo' tardiamente, pois, quando foram confrontadas com a expressão anafórica 'ele mesmo' e uma ação reflexiva ou recíproca, as respostas foram casuais, pois, em um momento, escolhiam a ação reflexiva e, em outro, a ação recíproca. 
Já com a forma 'se', os resultados tangenciaram para a escolha de acordo com a semântica do verbo. Uma explicação para esses resultados, segundo Grolla (2012), é que o 'se' é uma forma neutra, diferentemente do 'ele mesmo', e aquele é gerido pelo Princípio A da Teoria da Ligação, contrariamente ao 'ele mesmo', comandado por questões semânticas e pragmáticas.

Lacerda (2014), por meio de um experimento de leitura automonitorada (Self-paced Reading), analisou se os diferentes tipos de retomada (reflexiva se, nula - $\emptyset$, pronominal - ele ( $a$ )), a semântica do verbo (prováveis reflexivos e prováveis não reflexivos) e as diferenças dialetais entre Minas Gerais e Paraíba poderiam influenciar ou não o processamento correferencial de estruturas reflexivas. As sentenças usadas nesse trabalho, baseadas em Oliveira, Leitão e Henrique (2012), eram como as abaixo:

(7) a. Verbo provável reflexivo com retomada reflexiva (VRRR) Marcelo / machucou se no parque / de diversão. / Marcelo machucou a si mesmo?

b. Verbo provável reflexivo com retomada nula ( $\varnothing$ ) (VRRN) Marcelo / machucou na escola / de música. / Marcelo machucou a si mesmo?

c. Verbo provável reflexivo com retomada pronominal (VRRP)

Marcelo / machucou ele no parque / de diversão. / Marcelo machucou a si mesmo?

Os resultados apontam que houve um efeito significativo do tipo de retomada e de grupo (MG e PB). Ocorreu uma leitura reflexiva nas sentenças quando houve o absentismo do se e o uso do ele, com relação ao grupo de Minas Gerais, porém no grupo da Paraíba não houve a leitura reflexiva da ausência do se nem do uso do ele. Observou-se também uma forte probabilidade da influência da semântica verbal.
É importante destacar a influência semântica do verbo no processamento dessas sentenças. Observou-se a influência do tipo de predicado no processamento das retomadas nulas (RN), pois o tempo de leitura no segmento pós-crítico foi mais custoso. No grupo de Minas Gerais, o argumento foneticamente nulo foi interpretado como elemento anafórico, diferentemente do grupo da Paraíba, que considerou essas sentenças como agramaticais.

Nas condições com retomada reflexiva (RR), tanto no grupo de Minas Gerais como no da Paraíba, o tipo do verbo não marcado reflexivamente na presença da anáfora 'se' fez com que o tempo de leitura fosse maior. Uma explicação razoável para esse resultado é dado por Reinhart e Reuland (1993), os quais afirmam que um predicado marcado reflexivamente é reflexivo, ou seja, na presença da anáfora 'se', o predicado se torna reflexivo independentemente do tipo de verbo.

Com relação à retomada pronominal (RP), no grupo da Paraíba os resultados com relação aos dois tipos de verbos foram semelhantes. Porém, quando havia a ausência de um antecedente acessível sintaticamente e a presença de um verbo provável não reflexivo, a leitura da sentença não foi reflexiva no grupo da Paraíba, diferentemente do grupo de Minas Gerais. Nas condições VRRP - verbo provável reflexivo com retomada pronominal -, o pronome 'ele (a)' foi ligado localmente, e em VNRP - verbos prováveis não reflexivos com retomada pronominal -, foi ligado a um antecedente fora da sentença, no grupo de Minas Gerais. Os resultados mostram que a leitura foi mais lenta na condição VNRP.

Os dados encontrados por Lacerda (2014) evidenciam que o processamento da resolução da correferência ocorreu em dois estágios. Inicialmente - bonding - os princípios da Teoria da Ligação atuaram, porém de modo divergente dos resultados apontados por Nicol e Swinney (1989) e Oliveira, Leitão e Henrique (2012), pois, no trabalho de Lacerda 
(2014), houve influência de antecedentes indisponíveis na resolução da correferência, além da influência da semântica do verbo e da variação dialetal. No segundo estágio - resolution -, ocorreu o processamento dos mecanismos interpretativos. Diante disso, esse trabalho comprovou que tanto fatores sintáticos como semânticos, além da variação dialetal, podem influenciar no processamento sentencial.

\section{0 experimento}

O experimento realizado nesta pesquisa buscou encontrar evidências que comprovem a influência da semântica verbal - verbos ditos reflexivos - em estruturas que contêm a anáfora se, no português brasileiro (PB). Esse objetivo foi elaborado diante da necessidade investigativa de observar como a anáfora se se comporta diante de tais verbos, uma vez que alguns estudos encontraram influência tanto de fatores sintáticos como de fatores semânticos na aquisição e processamento de expressões anafóricas (GROLLA, 2012; LACERDA, 2014).

Foi feito um experimento offline de julgamento de aceitabilidade no intuito de estabelecer qual verbo é considerado mais aceitável no português brasileiro aliado à anáfora $s e$, utilizando-se apenas os verbos do nível de reflexividade secundário de acordo com os estudos de Christiano (1991) e Mello (2008). Para tanto, dividimos as sentenças em três tipos: presença do verbo secundário ${ }^{8}$ com o reflexivo 'se' (SecCSE), presença do verbo secundário sem o reflexivo 'se' (SecSSE) e uma sentença controle.

\footnotetext{
${ }^{8}$ Neste experimento utilizamos apenas os verbos que pertencem ao grupo secundário, visto que Henrique (2016) encontrou evidências da influência desse nível de reflexividade na decisão dos falantes nos julgamentos de aceitabilidade.
}

\subsection{Método}

O experimento offline foi elaborado na plataforma online Google Forms. Nesse experimento foi solicitado que os participantes lessem, de maneira natural, as sentenças e selecionassem uma opção de acordo com sua intuição. Foi apresentada uma lista com 30 sentenças e, em cada uma delas, cinco opções: (1) Mais aceitável; (2) Aceitável; (3) Pouco aceitável; (4) Menos aceitável; (5) Não aceitável. Nesse teste apresentamos cinco opções de resposta, como forma de deixar mais categórica a escolha da aceitabilidade das frases pelos falantes. 0 teste foi enviado para cada participante por $e$-mail e, no final de cada questionário, havia a opção 'enviar' finalizando o teste.

\subsection{Material}

O material utilizado neste experimento foram 30 frases experimentais. Dentre estas, 10 frases eram com o reflexivo 'se', 10 sem o reflexivo e 10 sentenças com sintagmas nominais como controle. Os verbos de todas as sentenças pertencem ao grupo verbal secundário, conforme a nomenclatura de Christiano (1991) e Mello (2008). O participante deveria selecionar uma opção dentre as cinco apontadas.

\subsection{Participantes}

Participaram deste teste offline 30 alunos graduandos de diferentes cursos da Universidade Federal da Paraíba (UFPB), Campus I, João Pessoa, bem como de algumas faculdades particulares da cidade, com idade entre 18 e 30 anos, todos falantes nativos do português brasileiro.

\subsection{Resultados e discussão}

Os resultados do experimento apontam o número de julgamentos para cada condição e foram submetidos à análise da variância (Anova e Teste 
de Qui-Quadrado de Homogeneidade). Diante dos dados analisados, não encontramos efeito significativo com relação ao tipo de verbo e, sim, com relação à retomada anafórica se.

Conforme o teste realizado, observamos que o tipo verbal estabelecido nos trabalhos de Christiano (1991) e Mello (2008) não influenciou a aceitação ou não das sentenças com a anáfora se. Os resultados apontaram para uma maior aceitabilidade das sentenças, quando estas possuíam o reflexivo 'se', independentemente do tipo de verbo.

Analisando e comparando os julgamentos de todas as condições experimentais (SecCSE; SecSSE e Controle - Gráfico 1), verificamos uma maior aceitação das sentenças que continham a retomada anafórica 'se'.

Gráfico 1 - Comparação dos julgamentos entre todas as condições.

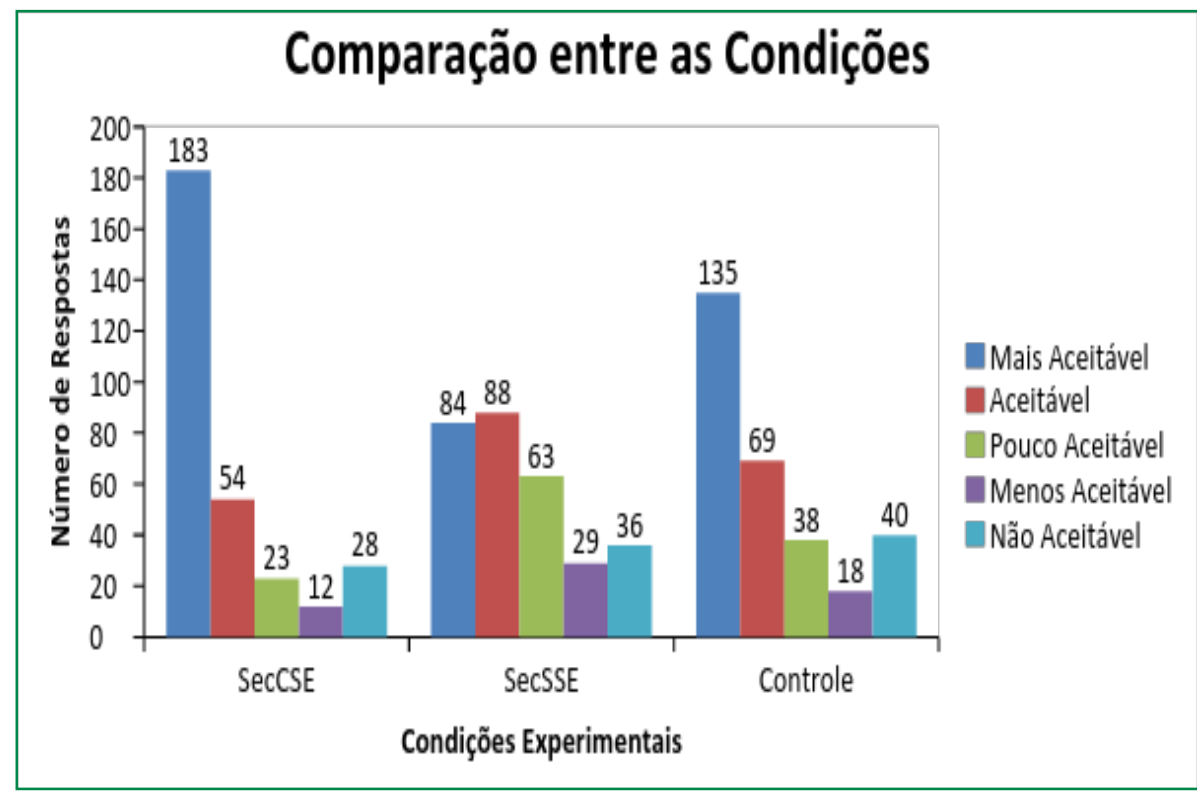

Assim como na comparação com todas as condições experimentais, apontadas no Gráfico 1, os dados encontrados na comparação entre as condições SecCSE e SecSSE mostraram uma maior aceitação para a condição em que o se estava presente, conforme podemos observar no Gráfico 2:

Gráfico 2 - Comparação dos julgamentos entre as condições SecCSE e SecSSE.

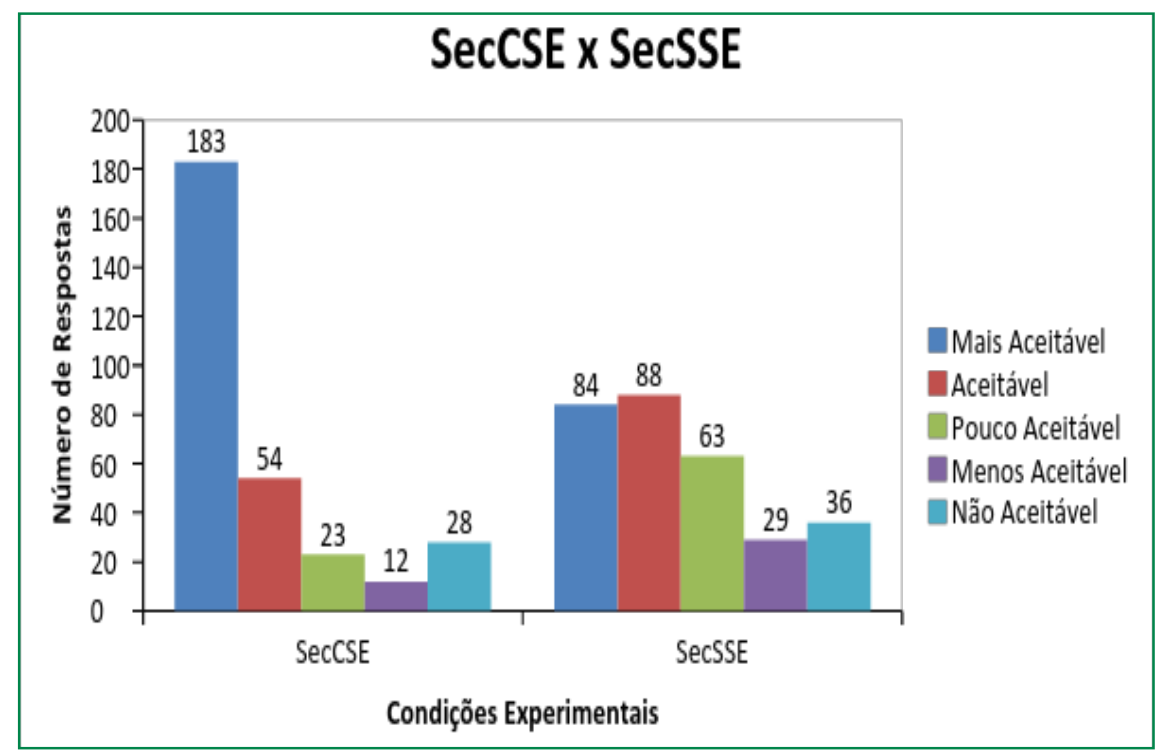

Analisando os dados encontrados na comparação entre as condições SecCSE e Controle, fica evidente que a anáfora se possui características próprias que a tornam reflexiva independentemente do tipo de verbo ao qual ela se agregue.

Tendo como base os dados apontados anteriormente na comparação entre as condições SecCSE e SecSSE, decidimos comparar como ocorre a aceitabilidade das sentenças com e sem o se e a sentença controle, conforme podemos visualizar nos Gráficos 3 e 4 a seguir: 
Gráfico 3 - Comparação dos julgamentos entre as condições SecCSE e Controle.

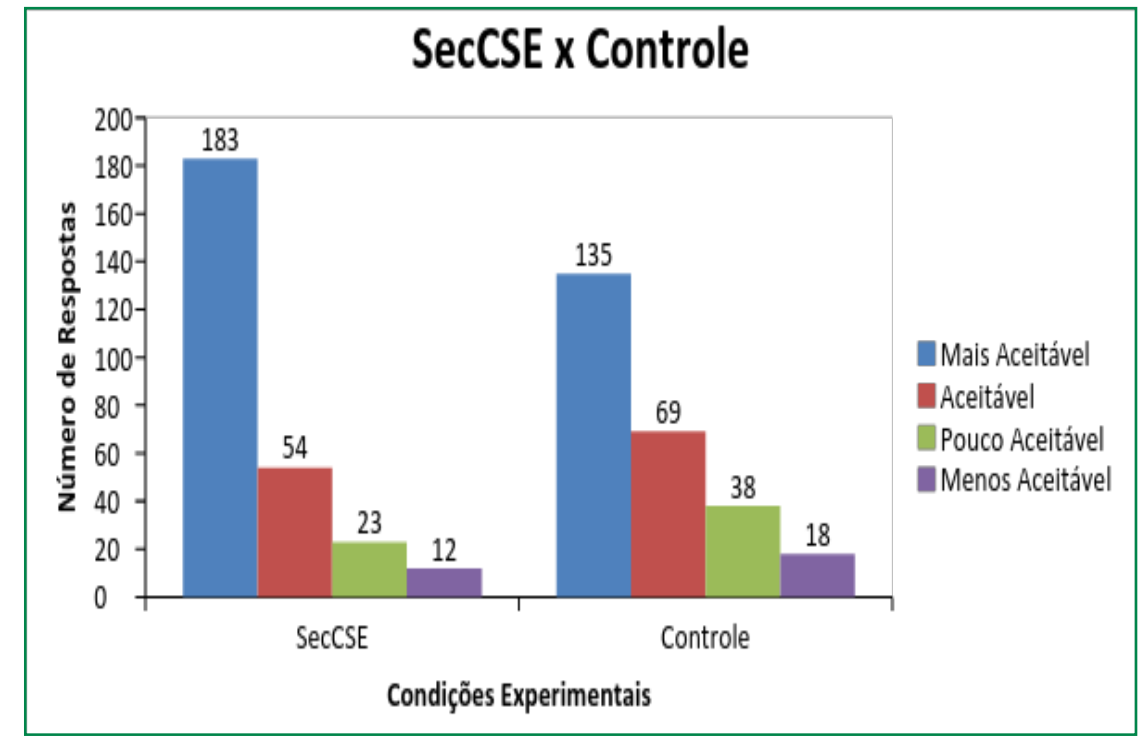

Gráfico 4 - Comparação dos julgamentos entre as condições SecSSE e Controle.

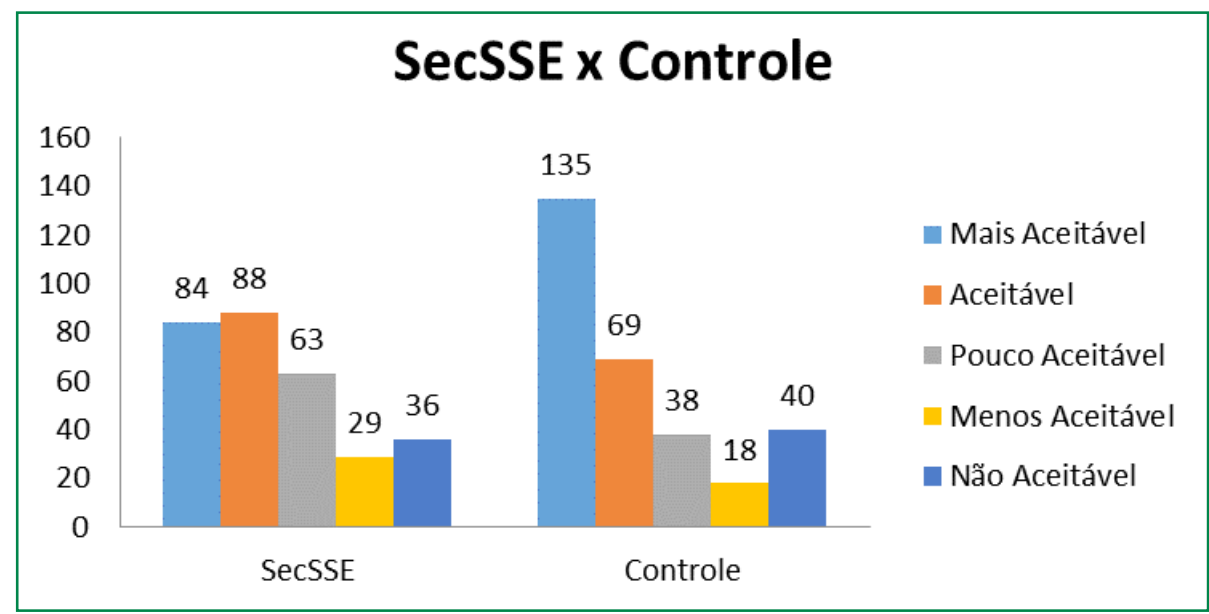

Com relação à comparação entre as condições SecCSe e a Controle, verificamos que a condição SecCSE foi considerada mais aceitável, assim como ocorreu na comparação entre SecCSE e SecSSe (Gráfico 2).

Os dados apresentados acima apontam que apenas a condição com a anáfora se é considerada mais aceitável pelos falantes nativos do português brasileiro.

\section{Discussão geral}

Os resultados obtidos a partir do teste de julgamento de aceitabilidade descrito acima afirmam que o maior número de julgamentos mais aceitáveis foi nas condições em que tínhamos a presença da anáfora se, independentemente do tipo de verbo - classificação estabelecida nos trabalhos de Christiano (1991) e Melo (2008). De modo geral, a maior aceitabilidade se deu nas condições em que tínhamos um verbo do tipo secundário e a anáfora se (SecCSE).

Assim, observamos que, na comparação dos julgamentos de todas as condições, a condição mais aceitável foi SecCSe - secundário com a anáfora se. Assim como na comparação das condições SeCSE e SecSSE, a escolha se deu pela condição com o reflexivo se. Os resultados tangenciaram para uma maior aceitação da anáfora se, pelo fato de esta ser mais usual, isto é, mais frequente na língua portuguesa, o que facilita a escolha dos falantes nativos do português brasileiro.

Além disso, Brito (2011b) afirma que a anáfora se possui um traço SELF, definido como semântico e que possui a propriedade de reflexivizar o predicado ao qual esteja contido. Assim podemos explicar os resultados obtidos neste teste, pois a anáfora se reflexiviza o predicado, não havendo a necessidade de obtermos um item lexicalmente reflexivo, neste caso, o verbo, assim como afirma $R \& R(1993)$. 
Comparando a condição SecCSE e uma sentença Controle, a condição mais aceitável foi aquela em que tínhamos a presença da anáfora se, bem como na comparação SecSSE e uma sentença Controle, em que os resultados tangenciaram para a condição Controle. Os resultados confirmam o que aponta Said Ali: "Às vezes a mera supressão do pronome é o bastante para dar ao verbo o perfeito caráter intransitivo [...]” (SAID ALI, 2008, p. 104). Isto é, pelo fato do verbo tornar-se intransitivo com a retirada do se, o que o torna reflexivo é, justamente, a presença do elemento anafórico.

Acreditamos que as anáforas possuem um grau de reflexividade maior do que o componente reflexivo lexicalmente marcado no verbo, fazendo com que a aceitabilidade tenha se dado pela presença da anáfora e não pela influência da semântica verbal.

Em suma, os resultados apontados acima afirmam uma maior aceitação da anáfora se, independentemente do tipo de verbo. Assim como postula R\&R (1993) e Brito (2011), a anáfora se possui um traço SELF no léxico que a faz transformar um predicado transitivo em reflexivo. 0 teste apontou que a anáfora se possui características intrinsecamente reflexivas que possibilitam uma interpretação reflexiva do predicado independentemente do tipo de verbo.

\section{Considerações finais}

Os resultados que apresentamos neste estudo tiveram como objetivo comprovar a influência de fatores semânticos, como o tipo de verbo, na leitura de sentenças reflexivas contendo a anáfora se. Para tanto, trouxemos a noção de reflexividade apontada por R\&R (1993) e os trabalhos de cunho funcionalista de Christiano (1991) e Mello (2008).

Como forma de percorrer os estudos e as bases teóricas que circundam os estudos em processamento anafórico, apresentamos a teoria gerativista de Chomsky (1981), a Teoria da Ligação - Binding Theory, para mais adiante compreendermos que não são apenas aspectos sintáticos que influenciam o processamento anafórico, no português brasileiro, em especial, mas que outras questões estão envolvidas, como a semântica.

Fundamentados em resultados de estudos sobre a influência do tipo verbal no português brasileiro, como Grolla (2012) e Lacerda (2014), os quais predizem que o tipo de verbo - sendo este mais ou menos reflexivo influencia na aquisição e no processamento anafórico, decidimos aprofundar esse debate. Outros trabalhos apontam apenas a influência de fatores sintáticos no processamento das anáforas, como os de Nicol e Swinney (1989), na língua inglesa, e os de Oliveira, Leitão e Henrique (2012), no português brasileiro.

Os resultados apontados aqui nos induzem a pensar que as sentenças foram consideradas mais reflexivas devido à presença da anáfora se, independentemente do tipo de verbo, e que isto pode ter se dado pela presença do traço SELF na anáfora.

Percebemos ainda que a Teoria da Ligação não é suficiente para explicar a influência de questões semânticas no processamento sentencial com anáforas. Para tanto, recorremos aos trabalhos de R\&R (1993), que trazem outra definição para predicados reflexivos, pois predizem que a propriedade da reflexividade não está ligada aos nominais, mas sim ao predicado. Embasados nessa perspectiva, confirmamos que não só a posição da anáfora nas sentenças é suficiente para que o predicado se torne reflexivo, mas que seu traço semântico atua na interpretação de sentenças reflexivas.

Por fim, acreditamos que fatores semânticos como o traço SELF marcado nas anáforas, como prediz R\&R (1993) e confirmado nos estudos de Brito (2011), foram atuantes na interpretação de sentenças reflexivas. 


\section{Referências}

ALI, Manuel Said. Dificuldades da língua portuguesa. Rio de Janeiro: ABL: Biblioteca Nacional, 2008. p. 260. (Coleção Antônio de Morais Silva, 7).

BRITO, Dorothy Bezerra Silva. Predicados reflexivos e compartilhamento de traços. Estudos Linguísticos, São Paulo, v. 40, p. 220-230, 2011a.

BRITO, Dorothy Bezerra Silva. Propriedades Referenciais do Reflexivo SE no Português Brasileiro. Leitura (UFAL), v. 1, p. 92-108, 2011b.

CHOMSKY, Avram Noam. Lectures on government and binding. Dordrecht: Foris, 1981.

Knowledge of language: its nature, origin and use. London, UK: Praeger, 1986.

CHRISTIANO, Maria Elizabeth Affonso. As estruturas reflexivas em português e seu tratamento na gramática dos casos profundos. Tese (Doutorado em Linguística) - UNESP, Araraquara, 1991.

CUNHA, Maria Angélica Furtado da; BISPO, Erivaldo Balduíno; SILVA, José Romerito. Linguística funcional centrada no uso: conceitos básicos e categorias analíticas. In: CEZARIO, Maria Maura; CUNHA, Maria Angélica Furtado da. Linguística centrada no uso: uma homenagem a Mário Martelotta. Rio de Janeiro: Mauad X: FAPERJ, 2013.

FALTZ, Leonard. Reflexivition: a study in universal grammar. New York: Garland, 1985.

GROLLA, Elaine. Estratégias infantis na aquisição da expressão "Ele Mesmo" em Português Brasileiro. Revista Linguística, Programa de Pós-Graduação em Linguística da Universidade Federal do Rio de Janeiro, v. 8, n. 2, 2012.

KENEDY, Eduardo. Curso básico de linguística gerativa. São Paulo: Contexto, 2013.

LACERDA, Maria Cláudia. O processamento da anáfora se em português brasileiro: comparando dados de Minas Gerais e Paraíba. Dissertação (Mestrado em Linguística) Universidade Federal da Paraíba, João Pessoa, 2014.

LACERDA, Maria Cláudia; OLIVEIRA, Rosana Costa de.; LEITÃO, Márcio Martins. O processamento da anáfora intra-sentencial em português brasileiro. Fórum Linguístico, Florianópolis, 2014.

MELLO. Fernanda Rosário de. O clítico reflexivo em manuscritos do século XIX: uma análise funcional. Revista Prolíngua, p. 36-46, 2008.
NICOL, Janet; SWINNEY, David. The role of structure in coreference assignment during sentence comprehension. Journal of Psycholinguistic Research, p. 5-20, 1989.

OLIVEIRA, Rosana Costa de; LEITÃO, Márcio Martins; HENRIQUE, Judithe Genuíno. A influência dos antecedentes vinculados e não vinculados no processamento da anáfora 'a si mesmo(a)'. Linguística, v. 8, n. 2, p. 115-134, 2012.

REINHART, Tania.; REULAND, Eric. Reflexivity. Linguistic Inquiry, n. 24, p. 657-720, 1993.

Recebido em: $17 / 03 / 2017$

Aceito em: 21/07/2017 